\title{
SUSTRACCIÓN INTERNACIONAL DE MENORES. ASUNTO VINCULADO CON SUIZA Y ESPAÑA. COMENTARIO DE LA SENTENCIA DE LA AUDIENCIA PROVINCIAL DE PONTEVEDRA (SECCIÓN 1ª) NÚM. 52/2018, DE 17 DE ABRIL
}

\author{
INTERNATIONAL CHILD ABDUCTION. CASE RELATED \\ WITH SWITZERLAND AND SPAIN. COMMENT ON THE \\ JUDGMENT OF THE SPANISH COURT OF APPEAL OF \\ PONTEVEDRA (SECTION 1) NUMBER 52/2018 OF $17^{\text {th }}$ APRIL
}

\author{
CARMen AzCÁRraga Monzonís \\ Profesora Titular de Derecho internacional privado \\ Universitat de València
}

Recibido: 17.01.2019 / Aceptado: 25.01.2019

DOI: https://doi.org/10.20318/cdt.2019.4638

\begin{abstract}
Resumen: Sustracción internacional a España de menor residente en Suiza en aplicación del Convenio de La Haya de 1980 sobre los aspectos civiles de la sustracción internacional de menores. Discrepancia sobre la residencia habitual del menor. No se aprecian motivos de no retorno.

Palabras clave: sustracción internacional de menores, Convenio de La Haya sobre sustracción, Convenio de La Haya sobre responsabilidad parental y protección de menores, residencia habitual

Abstract: International abduction to Spain of a minor residing in Switzerland under the Hague Convention on the Civil Aspects of International Child Abduction of 1980. Discrepancy about the habitual residence of the minor. No grounds for return denial are appreciated.

Keywords: international child abduction, Hague Convention on Child Abduction, Hague Convention on parental responsibility and measures of the protection of children, habitual residence

Sumario: I. Introducción. II. Hechos. III. Consideraciones jurídicas. 1. La aplicación al presente asunto del Convenio de La Haya de 1980 sobre sustracción internacional de menores. 2. La residencia habitual en la sustracción internacional de menores. 3. La denegación del retorno en la sustracción internacional de menores. IV. Valoración final.
\end{abstract}

\section{Introducción}

1. La Audiencia Provincial de Pontevedra estimó el 17 de abril de 2018 un recurso de apelación en un asunto sobre la sustracción internacional de un menor vinculado con Suiza y España, dos países contratantes del Convenio de La Haya de 1980 sobre los aspectos civiles de la sustracción internacional de menores ${ }^{1}$. En el mismo se plantea la eventual sustracción del menor por parte del padre desde Zúrich a Vigo, en el marco de una familia conformada por un hombre y una mujer inscritos como pareja

${ }^{1}$ BOE núm. 202, de 24 de agosto de 1987. 
de hecho en la provincia de Pontevedra. Estos hechos serán ampliados en el presente comentario en el apartado segundo (II) y a continuación se analizarán determinadas consideraciones jurídicas extraídas de la lectura de la sentencia (III), como son 1. La aplicación al presente asunto del Convenio de La Haya de 1980 sobre sustracción internacional de menores, 2. La residencia habitual en la sustracción internacional de menores, y 3 . La denegación del retorno en la sustracción internacional de menores. Finalizaremos este comentario con una valoración.

\section{Hechos}

2. La sentencia objeto de comentario recoge en el Fundamento de Derecho segundo los hechos del asunto que no son controvertidos, los cuales parten del nacimiento del menor en Vigo en 2015. El mismo ostenta la nacionalidad española, al igual que sus padres, quienes, como adelantábamos en la introducción, se encuentran inscritos en el registro de parejas de hecho de la provincia de Pontevedra desde el 20 de abril de 2015. La convivencia de la pareja finalizó en agosto de 2016. El menor residió en España desde su nacimiento, donde consta su matrícula en distintas escuelas infantiles, hasta que la madre lo trasladó el 20 de diciembre de 2016 a Zúrich.

3. En enero y julio de 2017 el padre solicitó la adopción de distintas medidas relacionadas con la pareja y dicho traslado. Sin embargo, se le notificó, primero, en relación con la demanda more uxorio que no era posible practicar la comisión rogatoria para emplazamiento de la demandada puesto que para ello era necesario conocer la dirección exacta y el cantón suizo y, segundo, por lo que respecta a la denuncia interpuesta por sustracción de menor, el sobreseimiento de las diligencias por la falta de concurrencia de los elementos del tipo penal dado que por entonces no existía resolución judicial que atribuyese la custodia a ningún progenitor. El 12 de enero de 2018 el padre viajó a Suiza para visitar a su hijo, trasladándolo a España la madrugada del día 14 sin contar con el consentimiento de la madre. El 16 de enero compareció ante el Juzgado de Guardia para comunicar que el menor se encontraba en España.

4. Acontecidas las circunstancias anteriores, que, como señalábamos, no son controvertidas, la madre solicitó ante los tribunales españoles la restitución inmediata del menor a Suiza, país que, argumentaba, constituyó su última residencia habitual, instando a que se declarara ilícito el traslado del menor por su padre a España. El demandado se opuso a la restitución alegando que la madre se había llevado previamente al menor a Suiza sin su consentimiento.

5. Con fecha 8 de marzo de 2018, el Juzgado de Primera Instancia núm. 5 de Pontevedra dictó sentencia desestimando la demanda interpuesta por la madre. Tras la práctica de la prueba previamente admitida, el tribunal consideró que no había existido un traslado ilícito por parte del padre en virtud del Convenio de La Haya de 1980 sobre los aspectos civiles de la sustracción internacional de menores por cuanto para ello la madre debería tener atribuido el derecho de custodia vulnerado, lo que no se consideraba en este caso pues, previamente, la misma se había llevado al menor de España a Suiza sin el conocimiento ni el consentimiento del padre, el cual era necesario -o en su defecto autorización judicialpara llevar a cabo dicho traslado. El tribunal de instancia tampoco considera por esta misma razón que el menor tenga su residencia habitual en Suiza.

6. Disconforme con dicho fallo, la madre interpone recurso de apelación alegando la incorrecta aplicación del Convenio de La Haya sobre sustracción, sosteniendo que decidió irse a vivir a Suiza seis meses después de romper la relación de pareja con el demandado, tras avisarle de tal intención y sin que él le manifestara su oposición de manera expresa. Considera además que esta decisión estuvo justificada por el interés del menor, trasladando a Suiza su residencia, que, en el momento de los hechos que se denuncian, era su residencia habitual. A este recurso se oponen tanto el demandado como el Ministerio Fiscal. 


\section{Consideraciones jurídicas}

7. Descritos los hechos, analizaremos a continuación las consideraciones jurídicas que hemos considerado más relevantes tras una detenida lectura de la sentencia objeto de comentario.

\section{La aplicación al presente asunto del Convenio de La Haya de 1980 sobre sustracción interna- cional de menores}

8. De acuerdo con el artículo 1 del Convenio de La Haya sobre sustracción internacional de menores, la finalidad del mismo es doble y consiste en a) garantizar la restitución inmediata de los menores trasladados o retenidos de manera ilícita en cualquier Estado contratante y b) velar por que los derechos de custodia y de visita vigentes en uno de los Estados contratantes se respeten en los demás. Partiendo de esta base, la aplicación del Convenio a un asunto en particular dependerá fundamentalmente de tres presupuestos básicos: 1) que el asunto se vincule con dos estados contratantes; 2) que el menor al que hace referencia cumpla con los parámetros exigidos en el mismo; y 3) que el traslado o retención del menor se consideren efectivamente ilícitos en cumplimiento de los requisitos establecidos en el propio texto.

9. Comenzando con el primero de los presupuestos, cabe advertir que para ser aplicado al asunto en cuestión el Convenio ha de estar vigente en los países de origen y destino de la sustracción. En el momento de escribir estas líneas los países vinculados por el mismo ascienden a noventa y nueve, incluyendo Suiza y España, en los que entró en vigor el 1 de enero de 1984 y el 1 de septiembre de 1987 respectivamente ${ }^{2}$. Este Convenio ha sido ampliamente ratificado a nivel mundial constituyendo uno de los textos más exitosos de cuantos han sido adoptados en el seno de la Conferencia de La Haya de Derecho Internacional Privado. Cuenta con eficacia inter partes, de ahí que su extenso ámbito de aplicación geográfico redunde en un mayor éxito del sistema de cooperación de autoridades que diseña, las denominadas Autoridades Centrales, que se comunican con el objetivo de que la restitución del menor se produzca de la forma más satisfactoria y rápida posible ${ }^{3}$.

10. Cumplida la premisa anterior, resulta necesario señalar, además, que el Convenio sobre sustracción delimita el perfil del menor sujeto de protección con base en dos elementos: su lugar de residencia y la edad máxima que puede haber alcanzado. De este modo, en virtud del artículo 4, el Convenio se aplicará a todo menor que tuviera su residencia habitual en un Estado contratante inmediatamente antes de la infracción de los derechos de custodia o de visita, dejando de aplicarse cuando alcance la edad de dieciséis años. Nos detendremos más adelante en la determinación de dicha residencia habitual, la cual, ya lo adelantamos, no siempre será fácil de concretar. Lo que sí queda meridianamente claro a la luz de lo establecido en dicho precepto es que no se deberán aplicar los criterios nacionales (sustantivos o de conflicto de leyes) para determinar quién ha de ser considerado "menor" a los efectos de la aplicación de este Convenio, ya que de acuerdo con esta norma, lo será el que tenga menos de dieciséis años.

11. Finalmente, un tercer presupuesto de aplicación a destacar se refiere al cumplimiento de los elementos exigidos por el artículo 3 del Convenio para considerar si el traslado o la retención del niño son efectivamente ilícitos. De acuerdo con el mismo, se considerarán ilícitos si se dan dos circunstancias de forma cumulativa: a) cuando se hayan producido con infracción de un derecho de custodia ${ }^{4}$ atribuido, separada o conjuntamente, a una persona, a una institución, o a cualquier otro organismo, con arreglo al

\footnotetext{
${ }^{2}$ Puede consultarse la situación actual de las ratificaciones en (última consulta el 3.1.2018):

https://www.hcch.net/es/instruments/conventions/status-table/?cid=24.

${ }^{3}$ Explica el modelo de cooperación del Convenio I. ReIG FABADO, "El retorno inmediato del menor en la sustracción internacional de menores", Revista Boliviana de Derecho, n² 20, 2015, p. 248.

${ }^{4}$ Nótese que de la interpretación conjunta de los artículos 4 y 21 del Convenio sobre sustracción se extrae que la protección del mismo se extiende asimismo a un derecho de visita eventualmente infringido. Artículo 21.I: "Una solicitud que tenga como fin la organización o la garantía del ejercicio efectivo del derecho de visita podrá presentarse a las Autoridades Centrales de los Estados contratantes, en la misma forma que la solicitud para la restitución del menor".
} 
Derecho vigente en el Estado en que el menor tenía su residencia habitual inmediatamente antes de su traslado o retención (el derecho de custodia puede resultar de una atribución de pleno derecho, de una decisión judicial o administrativa, o de un acuerdo vigente según el Derecho de dicho Estado); y, además, b) cuando este derecho se ejercía de forma efectiva, separada o conjuntamente, en el momento del traslado o de la retención, o se habría ejercido de no haberse producido dicho traslado o retención. En resumen, retomando el Fundamento de Derecho tercero de la sentencia analizada, "el Convenio exige un doble elemento: de un lado, la existencia de un derecho de custodia atribuido por el Estado de residencia habitual del menor, y de otro, el ejercicio efectivo de dicha custodia antes del traslado o retención".

12. La aplicación de esta norma al caso que nos ocupa, sobre todo de la primera condición, plantea dos problemas principales. Primero, establecer a qué progenitor corresponde la custodia a los efectos de su aplicación, aunque en caso de controversia se dilucide "el fondo del asunto" -la custodiaen un procedimiento distinto 5 . Y segundo y vinculado con el anterior, determinar dicha custodia "con arreglo al Derecho vigente en el Estado en que el menor tenía su residencia habitual inmediatamente antes de su traslado o retención", cuando precisamente el lugar de su residencia habitual es una cuestión controvertida. Ahondaremos sobre esta última cuestión en el siguiente apartado del presente comentario, centrándonos en este momento en la concreción de la custodia del menor para aplicar las condiciones del artículo 3 del Convenio de 1980. El Tribunal señala en el Fundamento de Derecho tercero de la sentencia -sin argumentar jurídicamente por qué procede a realizar este análisis ni cómo llega a ese convencimiento- que "ya se considere residencia habitual del menor España o Suiza", tanto el ordenamiento jurídico español como el suizo atribuyen la patria potestad conjunta a los padres, dentro de la cual se incardina el derecho a elegir el lugar de residencia, que debe hacerse de común acuerdo o, en su defecto, con autorización judicial. También en el Fundamento de Derecho cuarto se señala que "A salvo una prueba más detallada sobre el derecho civil suizo en esta materia, no se ha controvertido que el régimen de patria potestad, su ejercicio conjunto por ambos progenitores, y en concreto la necesidad de su acuerdo para decidir el lugar de residencia, es similar al español, de forma que para alterar la situación de la residencia habitual en Suiza en los términos antes expuestos a los efectos de los Convenios de La Haya citados, era necesario el acuerdo de ambos progenitores o, en su defecto, autorización judicial". Por lo tanto, aun sin esclarecer cuál sería el Derecho aplicable a esta cuestión ni cómo o por quién se ha probado en este asunto el Derecho suizo ${ }^{6}$-actuación manifiestamente mejorable-, el Tribunal considera que el consentimiento de ambos era necesario para el traslado.

\section{La residencia habitual en la sustracción internacional de menores}

13. La residencia habitual de un menor puede ser una de las cuestiones más complejas de determinar en los asuntos vinculados con diversos países, siendo, al mismo tiempo, un aspecto crucial en los casos sobre responsabilidad parental y sustracción internacional de menores ya que se trata de la conexión prevalente en los instrumentos reguladores de este sector. Lo hemos visto en este mismo asunto a la hora de aplicar el Convenio de La Haya sobre sustracción, pero también deviene esencial en la aplicación del Convenio de La Haya relativo a la competencia, la ley aplicable, el reconocimiento, la ejecución y la cooperación en materia de responsabilidad parental y de medidas de protección de los niños, hecho en La Haya el 19 de octubre de 19967 (aplicable en las relaciones con Suiza), así como en el contexto del Reglamento $n^{\circ}$ 2201/2003 relativo a la competencia, el reconocimiento y la ejecución de resoluciones judiciales en materia matrimonial y de responsabilidad parental (el llamado Reglamento

\footnotetext{
5 C.M. CAamiña Domínguez, "El interés superior del menor: la integración en el nuevo medio", Cuadernos de Derecho Transnacional, vol. 8, n 2, 2016, p. 86.

6 Véase sobre el régimen de la aplicación de Derechos extranjeros en España desde la reforma de 2015 C. AzCÁRRAGA MonzonIs, "Spain: The Application of Foreign Law in Spain - Critical Analysis of the Legal Novelties of 2015", en NISHITANI, Y.: Treatment of Foreign Law - Dynamics Towards Convergence?, Springer, Heidelberg, 2017.

7 BOE núm. 291, de 2 de diciembre de 2010. Convenio vigente en nuestro país desde el 1 de enero de 2011, así como en Suiza desde el 1 de julio de 2009. Información disponible en la Página Web de la Conferencia de La Haya de Derecho Internacional Privado (consultado el 13 de enero de 2019): https:/www.hcch.net/es/instruments/conventions/status-table/?cid=70.
} 
Bruselas II bis $)^{8}$, que acertadamente señala la sentencia que no resulta de aplicación a este asunto al no ser Suiza Estado parte de la Unión Europea.

14. Ninguno de los instrumentos anteriores define la residencia habitual, lo que parece una decisión acertada dada la gran casuística existente en esta materia y la conveniencia, por tanto, de valorar cada caso atendiendo a las particulares circunstancias fácticas. Ahora bien, esta postura también presenta un lado negativo que se concreta en dos aspectos. En primer lugar, la dificultad añadida que supone para los operadores jurídicos la determinación de la residencia habitual caso por caso. En segundo lugar, las interpretaciones divergentes de este concepto en los Estados contratantes del Convenio, lo que no favorece la previsibilidad ni la aplicación unitaria del mismo, pudiendo dar lugar al tratamiento desigual de asuntos con idéntico perfil. De hecho, se ha advertido cómo los Estados parte del Convenio sobre sustracción han puesto el foco en aspectos distintos para determinar la residencia habitual. Mientras algunos se han centrado exclusivamente en la figura del menor, otros han considerado principalmente la intención de los padres y un tercer grupo de países ha adoptado un enfoque combinado teniendo en cuenta los dos elementos anteriores?.

15. En el ámbito de la Unión Europea, aunque el caso que nos ocupa escape de su alcance, resulta necesario mencionar la jurisprudencia del Tribunal de Justicia de la Unión Europea que ha permitido armonizar los criterios utilizados para acotar la residencia habitual del menor, si bien siempre con base en la valoración de los aspectos fácticos relevantes en cada asunto. La residencia habitual ha de interpretarse como el lugar donde el menor tenga "cierta integración" en un entorno social y familiar. Por ello, resultaría pertinente considerar aspectos como la duración, la regularidad, las condiciones y razones de la permanencia en el territorio, así como los motivos del traslado de la familia a dicho Estado, la nacionalidad del menor, el lugar y las condiciones de escolarización, sus conocimientos lingüísticos o las relaciones familiares. En el caso de un lactante que se encuentra con su madre tan solo unos días antes de haber sido trasladado a otro Estado miembro distinto del Estado de su residencia habitual, debe considerarse, por un lado, la duración, la regularidad, las condiciones y las razones de la estancia y del traslado y, por otro lado, los orígenes geográficos y familiares de la madre, así como las relaciones familiares y sociales de la madre y el menor en dicho Estado ${ }^{10}$.

16. En el presente asunto, la Audiencia Provincial considera, a diferencia de la sentencia de instancia, que es indudable que el niño residía en Suiza, con base en distintos factores. Primero, porque fue allí donde fue llevado por su madre, lo que ha sido comprobado por el propio demandado. Segundo, porque fue allí a donde viajó el padre para traerlo nuevamente a España, sin que exista dato alguno que haga pensar que el menor residió en otro país. Además, considera que fue precisamente en Suiza donde se encontró arropado en un marco familiar al residir allí su abuela, un tío y una prima. Pero lo más relevante, continúa, es que es en Suiza donde ha residido con su madre, no solo durante este tiempo sino también antes, cuando cesó la convivencia de los progenitores en agosto de 2016, cuando el menor, que contaba casi un año y medio de edad, quedó al cuidado de su madre durante varios meses, hasta que en diciembre de ese año fue trasladado a Suiza por esta, con la que siguió conviviendo algo más de un año hasta que el padre lo trajo nuevamente a España. Es decir, el Tribunal considera que "la integración con su madre y con la familia de esta en Suiza estaba consolidada, no pudiendo exigirse nada más en relación a una integración cuando de menores de corta edad se trata, cuyo mundo relacional se centra esencialmente en las personas bajo cuya guarda se encuentran" (Fundamento de Derecho quinto).

\footnotetext{
${ }^{8}$ DOUE L 338, de 23 de diciembre 2003.

9 Información disponible en Análisis de jurisprudencia INCADAT (consultado el 13 de enero de 2019): https://www. incadat.com/es/convention/case-law-analysis.

${ }^{10}$ Recoge estos criterios M. GuZMÁn PecEs, "Problemática en la coordinación de los instrumentos normativos aplicables a la sustracción de menores y en particular a la interpretación de la residencia habitual", Anuario Español de Derecho Internacional Privado, t. XIV-XV, 2014-2015, pp. 510 y 512.
} 


\section{La denegación del retorno en la sustracción internacional de menores}

17. Tal y como advertimos anteriormente y procede recordar en este momento, el artículo 1 del Convenio de La Haya sobre sustracción contempla como finalidad garantizar la restitución inmediata de los menores trasladados o retenidos de manera ilícita en cualquier Estado contratante. La filosofía de este instrumento convencional es meridianamente clara: el menor ha de ser devuelto cuanto antes al lugar del que ha sido sustraído (el de su residencia habitual), sin demora, con celeridad, y sin cuestionar en esta fase los derechos de custodia y visita, esto es, sin entrar en el fondo del asunto, ya que estas cuestiones deberán dilucidarse en un proceso diferente. De esta idea se extrae la importancia del factor tiempo, lo que se traduce principalmente en el establecimiento de procedimientos expeditivos, aunque no siempre se cumplan en la práctica. La urgencia impuesta por el sistema persigue, ante todo, minimizar los efectos negativos sobre el niño (en definitiva, todas las decisiones deben basarse en el principio del interés superior del menor) y evitar su integración en un nuevo medio, pero también impedir que el sustractor obtenga ventaja del paso del tiempo desde un punto de vista jurídico como consecuencia de lo anterior.

18. Si bien el modelo del Convenio de La Haya sobre sustracción gira en torno a la restitución inmediata del menor, el propio texto establece que en determinadas circunstancias, que deben ser interpretadas de manera restrictiva, esta podrá no ordenarse. Así, señala el artículo 12 que aunque hubiere transcurrido un año desde el traslado ilícito a otro país, se deberá ordenar la restitución del menor "salvo que quede demostrado que el menor ha quedado integrado en su nuevo ambiente", lo que puede conllevar la denegación de esta solicitud ${ }^{11}$. También el artículo 20 en relación con el 12 establece que la restitución del menor podrá denegarse cuando no lo permitan los principios fundamentales del Estado requerido en materia de protección de los Derechos Humanos y de las libertades fundamentales. El artículo 13 añade, además, que la autoridad judicial o administrativa del Estado requerido no está obligada a ordenar la restitución del menor si se demuestra que a) el derecho de custodia no se ejercía de modo efectivo en el momento en que fue trasladado o retenido o había consentido o posteriormente aceptado el traslado o retención; o b) existe un grave riesgo de que la restitución del menor lo exponga a un peligro grave físico o psíquico o que de cualquier otra manera lo ponga en una situación intolerable ${ }^{12}$. Junto con ello, si el menor ha alcanzado una edad y un grado de madurez en que resulte apropiado tener en cuenta su opinión, la autoridad podrá asimismo negarse a ordenar su restitución si este se opone.

19. A la hora de valorar la eventual restitución del menor de España a Suiza, la Audiencia Provincial de Pontevedra considera principalmente que el menor está integrado en Suiza y no en España (por lo que no se constata esta excepción de no retorno del artículo 12) y además que los problemas de la madre con el alcohol no han colocado al menor en una situación de riesgo (por lo que tampoco se considera aplicable la excepción del artículo 13). Junto con lo anterior, no considera justificado que el padre procediera a sustraer al menor a España aduciendo que la madre lo había sustraído previamente al llevárselo a Suiza sin su consentimiento, ni siquiera aceptando que aquella conducta fue también objeto de un traslado ilícito ya que "una inicial sustracción ilícita, mantenida en el tiempo, genera, cuando se crea una situación de estabilidad, un estado también protegible por el ordenamiento, especialmente cuando trasluce una defensa del interés del menor, que no está viciado por aquella inicial sustracción ilícita" (Fundamento de Derecho cuarto).

20. Por todo lo anterior, analizados los hechos expuestos, atribuida la facultad de decidir sobre la residencia del niño a ambos progenitores -independientemente del Derecho regulador de esta cuestión y de cómo tendría que haber sido probado ante el juez- y constatada la integración del menor en Suiza y su consecuente residencia habitual en este país, el Tribunal declara que el traslado efectuado por el padre desde Zúrich a Vigo fue ilícito, procediendo la restitución del menor a la madre para su retorno a Suiza.

${ }^{11}$ Estudia esta causa J. Flores Rodríguez, "La integración en el nuevo medio como causa de denegación de la restitución en la sustracción internacional de menores", La Ley Derecho de Familia: Revista jurídica sobre familia y menores, $\mathrm{n}^{\circ}$ 10, 2016.

${ }^{12}$ Analiza esta causa E. Rodríguez Pineau, "La oposición al retorno del menor secuestrado: movimientos en Bruselas y La Haya", Revista electrónica de estudios internacionales, $\mathrm{n}^{\circ} 35,2018$, pp. 8 y ss. 


\section{Valoración final}

21. La sentencia de la Audiencia Provincial de Pontevedra objeto de este comentario evidencia una vez más las cuestiones principales que subyacen tras las disoluciones de las parejas internacionales con hijos menores. La pareja que se disuelve presenta vínculos con diversos países y no siempre llega a acuerdos sobre la determinación del lugar de residencia de los hijos comunes, dando lugar, en ocasiones, a su traslado a otro país sin el consentimiento del otro progenitor, como ha ocurrido en este asunto en dos ocasiones en poco tiempo. Cuando se dan estas circunstancias, los instrumentos reguladores de la sustracción internacional de menores, y en particular el Convenio de La Haya de 1980, juegan un papel primordial con el fin de minimizar los efectos negativos sobre el niño y evitar su integración en un nuevo medio. En definitiva se persigue el respeto del principio del interés superior del menor, que en este contexto se considera que pasa como regla general por que retorne con celeridad al lugar de su residencia habitual inmediatamente anterior al traslado o retención, dejando para un procedimiento diferente la concreta determinación de la custodia.

22. Ahora bien, aun siendo clara la finalidad perseguida, no siempre resulta sencilla de implementar en la práctica. En ocasiones no va a ser fácil determinar la residencia habitual del menor, teniendo el operador jurídico que valorar caso por caso al no existir un concepto legal en los instrumentos internacionales mencionados. Otras veces se podrán constatar situaciones que justifiquen que no se ordene la restitución, lo que exigirá un estudio exhaustivo de las circunstancias particulares que conduzcan a apoyar esta decisión. Todo ello independientemente de la atribución de los derechos de custodia y visita, que se resolverán en otro proceso de conformidad con el Derecho que resulte pertinentemente aplicable, una cuestión que, como se ha advertido, ha sido resuelta de forma deficiente en la sentencia analizada. 